\title{
Regression Analysis of the Effect of Bias Voltage on Nano- and Macrotribological Properties of Diamond-Like Carbon Films Deposited by a Filtered Cathodic Vacuum Arc Ion-Plating Method
}

\author{
Shojiro Miyake, ${ }^{1}$ Takanori Shindo, ${ }^{1}$ and Masatoshi Miyake ${ }^{2}$ \\ ${ }^{1}$ Nippon Institute of Technology, 4-1 Gakuendai, Miyasiro-machi, Saitama 345-8501, Japan \\ ${ }^{2}$ School of Management, Tokyo University of Science, Kuki-shi, Saitama 346-8512, Japan \\ Correspondence should be addressed to Shojiro Miyake; gosaburo@gmail.com
}

Received 21 September 2013; Accepted 12 December 2013; Published 28 January 2014

Academic Editor: Tianchang Hu

Copyright (C) 2014 Shojiro Miyake et al. This is an open access article distributed under the Creative Commons Attribution License, which permits unrestricted use, distribution, and reproduction in any medium, provided the original work is properly cited.

\begin{abstract}
Diamond-like carbon (DLC) films are deposited by bend filtered cathodic vacuum arc (FCVA) technique with DC and pulsed bias voltage. The effects of varying bias voltage on nanoindentation and nanowear properties were evaluated by atomic force microscopy. DLC films deposited with DC bias voltage of $-50 \mathrm{~V}$ exhibited the greatest hardness at approximately $50 \mathrm{GPa}$, a low modulus of dissipation, low elastic modulus to nanoindentation hardness ratio, and high nanowear resistance. Nanoindentation hardness was positively correlated with the Raman peak ratio $I_{d} / I_{g}$, whereas wear depth was negatively correlated with this ratio. These nanotribological properties highly depend on the films' nanostructures. The tribological properties of the FCVA-DLC films were also investigated using a ball-on-disk test. The average friction coefficient of DLC films deposited with DC bias voltage was lower than that of DLC films deposited with pulse bias voltage. The friction coefficient calculated from the ball-on-disk test was correlated with the nanoindentation hardness in dry conditions. However, under boundary lubrication conditions, the friction coefficient and specific wear rate had little correlation with nanoindentation hardness, and wear behavior seemed to be influenced by other factors such as adhesion strength between the film and substrate.
\end{abstract}

\section{Introduction}

Diamond-like carbon (DLC) films have attracted much attention as a surface coating due to their superior tribological properties [1]. DLC films exhibit outstanding tribological properties such as low friction, high hardness, and wear resistance [2]. Furthermore, improvement of the boundary lubrication properties of such films is also expected. For instance, in an attempt to maximize fuel efficiency of automobile engines by decreasing friction, DLC films on the shim of a follower series have been investigated. On comparing the lubrication properties of these films with those of other films, it was observed that hydrogen-free DLC films were readily obtained $[3,4]$. In the case of magnetic storage disks, wear and minute friction fluctuation diminishes equipment performance. An extremely thin wear and corrosion resistant film coated on these surfaces should be considered [5-7]. To achieve high recording density, a durable protective film should be less than $2 \mathrm{~nm}$ thick, and to achieve such thicknesses the filtered cathodic vacuum arc (FCVA) technique has been studied extensively [8-10].

Many methods have been applied to depositing DLC films. Films produced by the plasma chemical vapor deposition (CVD) method contain hydrogen; therefore to avoid this physical vapor deposition (PVD) methods such as arc ion plating (AIP) have been applied. When solid carbon is used as the vapor source, little hydrogen is found in the films. AIP is applied when there is a desire to improve the hardness and adhesion of the films using high energy plasma. With AIP, it is possible to deposit a tetrahedral amorphous carbon (ta-C) thin film, which is employed in the fabrication of automobile sliding parts and films that protect magnetic 
heads at a high speed. However, a disadvantage of AIP is that the surface roughness will be increased due to the deposition of macroparticles. In order to overcome this problem, a filter has been used in film deposition. Since FCVA was first reported as an efficient method for depositing high-quality hard coatings free of macroparticles, DLC films deposited by the FCVA method have generated considerable interest as coating materials $[11,12]$. Ion energy controlled by substrate bias is an important parameter in determining the properties of films deposited via the FCVA technique. The hardness and Young's modulus values for a ta- $\mathrm{C}$ film deposited at an ion energy of $75 \mathrm{eV}$ were 59 and $507 \mathrm{GPa}$, respectively [12].

In this study, DLC thin films were deposited via FCVA ion plating under both DC and pulse bias voltages. Then, the relationships between the structures and nano- and macrotribological properties of FCVA-DLC films deposited at various bias voltages were evaluated by regression analysis.

\section{Materials and Methods}

2.1. Deposition of DLC Films. DLC films were deposited by FCVA plating with a bended filter, a graphite target, and argon gas. The substrate was subjected to DC and pulse bias voltages during film deposition. To deposit smooth DLC films, the bended filter was applied to arc plasma from a graphite target. The high density arc plasma was applied while the target was irradiated. During this time, macroparticles were removed by the magnetic field through the pipe bended filter. For depositing films, a bias voltage, DC bias voltage from -50 to $-200 \mathrm{~V}$, or pulse bias voltage from -0.5 to $-2.0 \mathrm{kV}$ was applied on the substrate. The DLC films were also deposited under floating voltage and ground without bias voltage and were then compared with biased DLC films. To avoid the influence of surface roughness, the silicon (100) substrate was polished to give a mirror finish. The above-mentioned conditions resulted in a film thickness of approximately $200 \mathrm{~nm}$ and are listed in Table 1.

To clarify the structure of the FCVA-DLC film [12], Raman spectral measurements $\left(200-2000 \mathrm{~cm}^{-1}\right)$ were carried out [13] with a LabRAM Horiba Jobin Yvon spectrometer equipped with a CCD detector and a He-Ne laser $(532 \mathrm{~nm})$ at $5 \mathrm{~mW}$. All samples were analyzed at an exposure time of $100 \mathrm{~s}$ and with an aperture hole of $100 \mu \mathrm{m}$.

2.2. Evaluation of Nanoindentation Properties. Nanoindentation tests were carried out to evaluate the mechanical properties of FCVA-DLC films by atomic force microscopy (AFM: digital instrument with hysitron digital instrument). The Berkovich diamond indenter, which is a three-sided pyramid, was used with a load of $300 \mu \mathrm{N}$ and a tip radius of approximately $200 \mathrm{~nm}$. During the experiment, both the loading and unloading times were $5 \mathrm{~s}$. Maximum plastic deformation depth was evaluated from the nanoindentation curve, and the contact area (Ar) encircled by load curve, unload curve, and $X$-axis was calculated. Then, hardness $H$ was calculated as follows:

$$
H=\frac{P}{\mathrm{Ar}}
$$

TABLE 1: Deposition condition.

\begin{tabular}{|c|c|c|}
\hline \multirow{4}{*}{ Bias } & Direct current & -50 to $-200 \mathrm{~V}$ \\
\hline & Pulse bias & -0.5 to $-2.0 \mathrm{kV}$ \\
\hline & \multicolumn{2}{|c|}{ Ground, floating } \\
\hline & \multicolumn{2}{|c|}{ Film thickness: $\sim 200 \mathrm{~nm}$} \\
\hline
\end{tabular}

where $P$ is the applied load in the measurement. Young's modulus $E$ was obtained on the basis of inclination of the unloading curve in the nanoindentation test and the plasticity index [14] was defined as follows.

To clarify the deformation mechanism of FCVA-DLC films, an energy analysis of nanoindentation was performed [15]. Total deformation energy was calculated using the integral of the loading curve. Storage energy was calculated using the integral of the unloading curve and dissipated energy was calculated as the remainder of total energy minus the storage energy. The modulus of dissipation was calculated by dividing the dissipation energy by the total energy.

2.3. Nanowear Test. A nanowear test was performed to evaluate wear resistance at the nanometer scale using AFM $[2,11,16]$ as shown in Figure 1(a). The tip was supported by a parallel-leaf spring unit with a small spring constant. The diamond tip was slid against the specimen surface by lead zirconate titanate (PZT) scanner, which moved the sample for contact, loading, and scanning. Samples coated with DLC films were scanned by this scanner and the test conditions were as follows: the radius of the Berkovich diamond indenter tip was nearly $200 \mathrm{~nm}$, the load was $30 \mu \mathrm{N}$, the scan range was $500 \times 500 \mathrm{~nm}^{2}$, and the friction speed was $4.0 \mu \mathrm{m} / \mathrm{s}$. After the wear test, the nanowear volumes were measured by AFM from the change in surface profile measured at a load less than $1 \mu \mathrm{N}$. Then, the wear average depth was evaluated.

2.4. Tribological Test. A ball-on-disk type friction test was carried out to evaluate the tribological properties of FCVADLC films as shown in Figure 1(b). By rotating the sample with the application of a specific load on a $6 \mathrm{~mm}$ diameter SUS440C ball indenter, we measured the friction force using a strain gauge type friction sensor. The tribological properties of these DLC films under dry and boundary lubrication conditions were investigated. The dependence of frictional properties on rotation cycles was evaluated under conditions of a load of $5.0 \mathrm{~N}$, a rotation speed of $100 \mathrm{rpm}$, a rotation radius of $4 \mathrm{~mm}$, and a total number of rotating cycles of 6000 . The velocity was approximately $31.4 \mathrm{~mm} / \mathrm{s}$. The testing temperature was maintained near $293 \mathrm{~K}$. After the friction test, the wear traces of the samples were observed using an optical microscope and three-dimensional profile meter. Moreover, to investigate the boundary lubrication properties of DLC films, Z-20 lubricant with molybdenum dithiocarbamates (MoDTC) and water were used. 


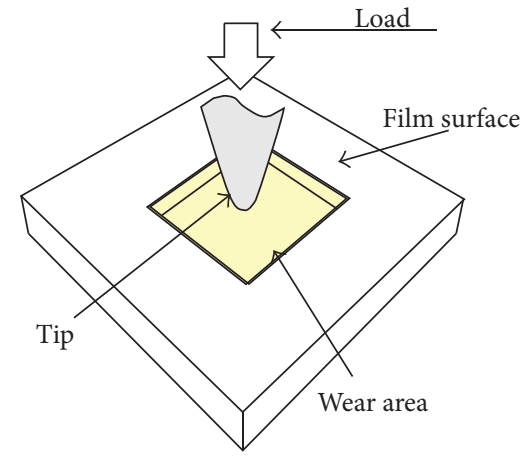

(a)

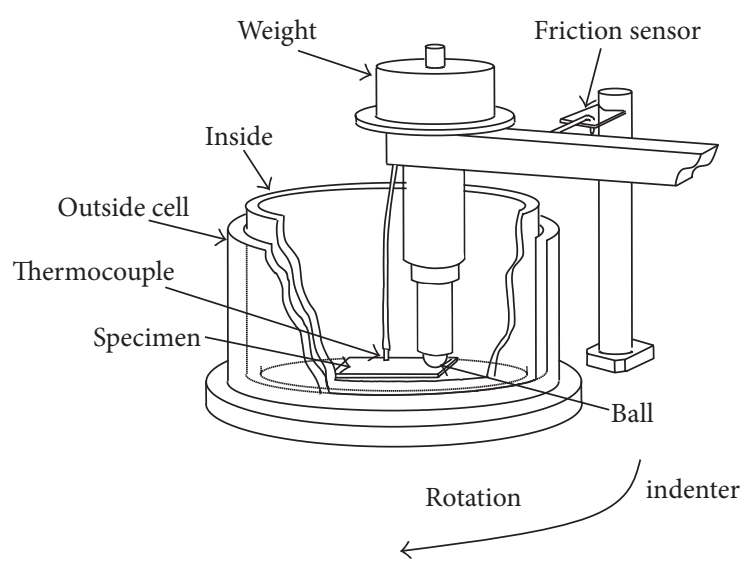

(b)

FIGURE 1: Schematic diagrams for (a) nanowear and (b) ball-on-disk tribotests.

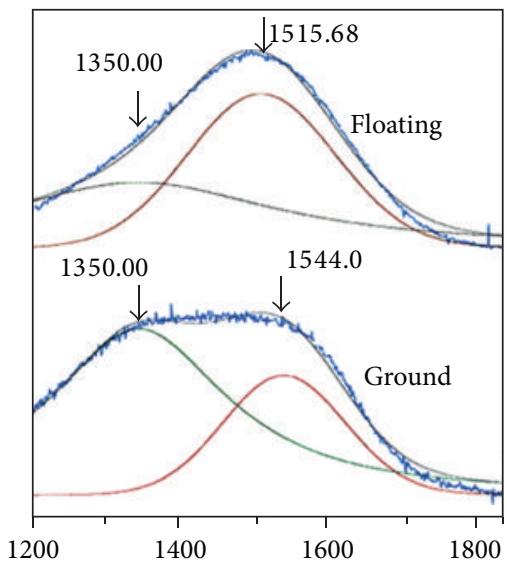

(a) Without bias

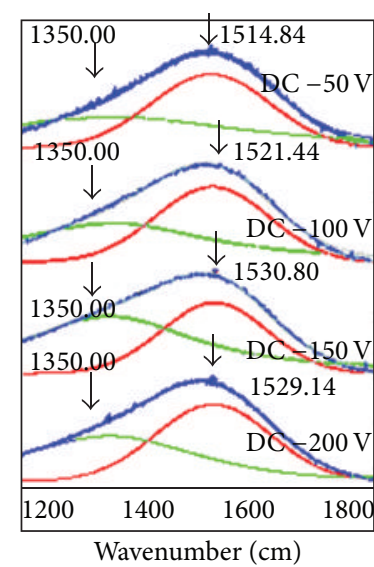

(b) DC bias

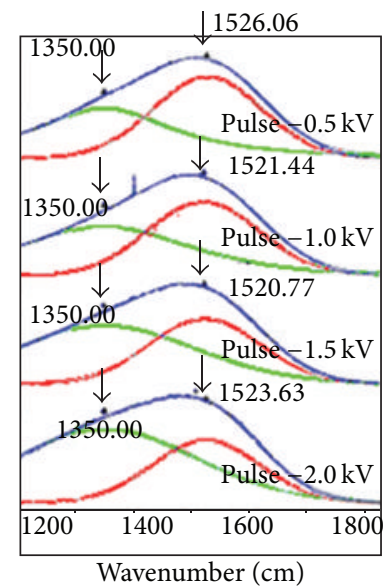

(c) Pulse bias

FIGURE 2: Raman spectra of DLC films deposited at various bias voltages.

\section{Results and Discussion}

\subsection{DLC Film Roughness and Structure}

3.1.1. Surface Roughness. To examine the surface roughness created by the macroparticles produced during DLC film deposition, surface profiles of coated samples were observed with AFM. Maximum roughness, Sy, and center-line average roughness, Sa, were evaluated. The roughness values of the DLC film deposited with ground were the highest at $5.3 \mathrm{~nm}$ Sy and $0.4 \mathrm{~nm} \mathrm{Sa}$, whereas those of the DLC film deposited with floating voltage were low at $1.5 \mathrm{~nm}$ Sy and $0.18 \mathrm{~nm}$ Sa. Under the floating condition, self biased voltages were induced. When the direct current bias voltage was applied during deposition, the surface roughness values were $1.5 \mathrm{~nm}$ Sy and $0.15 \mathrm{~nm}$ Sa. For DLC films deposited under pulse bias voltage, the roughness values were $1.8 \mathrm{~nm}$ Sy and $0.18 \mathrm{~nm}$ Sa. These results show that the macroparticles produced during deposition were removed by filtering and the roughness of DLC films deposited under both direct and pulse bias voltages were less than $2.0 \mathrm{~nm}$ Sy and $0.2 \mathrm{~nm}$ Sa.
3.1.2. Raman Spectra. Figure 2 shows the Raman spectra of DLC films prepared by the FCVA method with different target bias voltages. For all FCVA-DLC films deposited with pulse, floating, and DC bias voltages, the intensity of the peak at approximately $1580 \mathrm{~cm}^{-1}$ (Graphite- (G-) band) was higher than that of FCVA-DLC films deposited with ground. For these FCVA-DLC films, except the DLC film deposited with ground, the G-band peak intensity was very low, and no significant Disorder- (D-) band peak at approximately $1350 \mathrm{~cm}^{-1}$ was observed. However, for films deposited with ground, the intensity of the G-band peak was higher than those of other FCVA-DLC films. The G-band peak was due to the motion of the $\mathrm{sp}^{2}$ carbon in the graphite plane, and the D-band peak was due to the disorder of the structure. In addition, the G-band peak appeared to shift to the left with increasing bias voltage due to the distortion of atom bonds. Figure 3 illustrates the dependence of $I_{d} / I_{g}$ and $\mathrm{G}$ position on bias voltage. The $I_{d} / I_{g}$ of a DLC film deposited with ground was as high as $2.5 . I_{d} / I_{g}$ decreased to nearly 1.0 with the addition of bias voltage. Moreover, $I_{d} / I_{g}$ slightly increased with an increase in the DC bias voltage. DLC films 


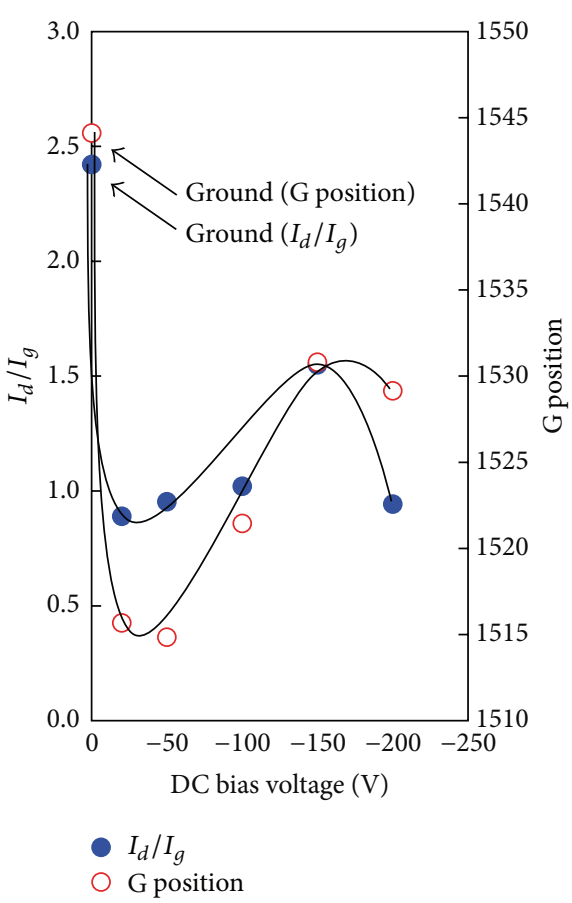

(a)

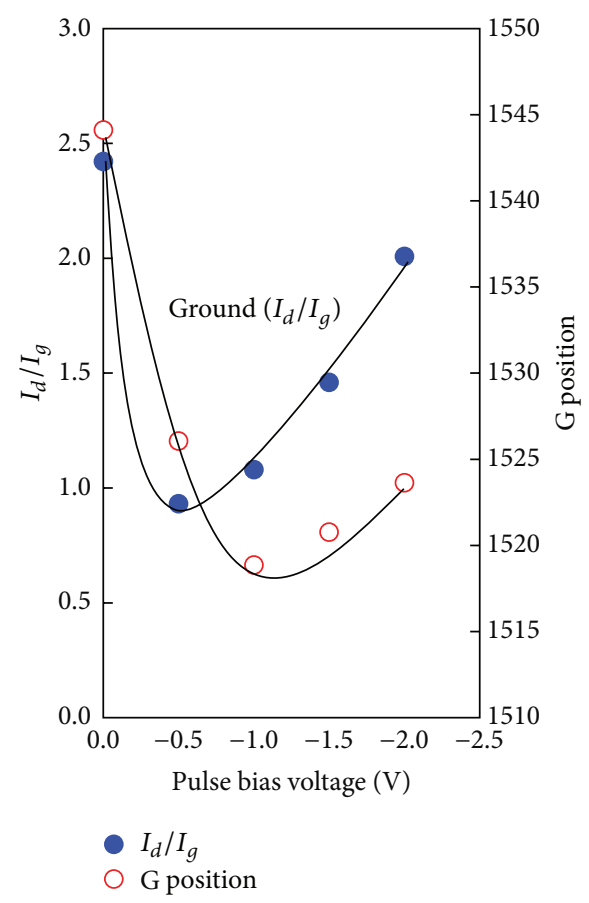

(b)

FIGURE 3: Effects of (a) DC bias voltage and (b) pulse bias voltage on $I_{d} / I_{g}$ and G position.

deposited at floating voltage showed low values of $I_{d} / I_{g}$ due to their self biased voltage. For pulse bias voltage, $I_{d} / I_{g}$ was as low as 1.0 at $-0.5 \mathrm{kV}$ and then increased with the pulse peak voltage. On the other hand, the $\mathrm{G}$ position was the lowest at $1515 \mathrm{~cm}^{-1}$ with floating and $-50 \mathrm{~V}$ DC bias voltage. For pulse bias voltage, the G position showed a similar trend as $I_{d} / I_{g}$ and was low at $-1 \mathrm{kV}$. The background noise caused by the polymeric structure in these films was also low, because the FCVA-DLC films were deposited via a hydrogen-free process. These results show that the FCVA-DLC films deposited with bias voltage contain significant $\mathrm{sp}^{3}$ bonding structures $[12$, 13].

3.2. Nanoindentation Properties. Nanoindentation hardness, $H$, is defined as the resistance to plastic deformation per unit area. Elastic modulus $(E) / H$ was evaluated because $E / H$ is the material parameter indicating the index of plasticity; thus, $E / H$ corresponds to the ease of plastic deformation. The average $H$ and $E / H$ values in this study are summarized in Figure 4. The $H$ values of DLC films with floating voltage and with ground were 45 and $29 \mathrm{GPa}$, respectively. DLC films deposited with DC bias voltage had higher $H$ than those of DLC films with ground. The DLC films exhibited a maximum $H$ of approximately $50 \mathrm{GPa}$ when the DC bias voltage was $-50 \mathrm{~V}$, and the hardness of these films decreased with increasing DC bias voltage. For the pulse bias voltage, DLC films had a maximum hardness when the peak voltage was $-0.5 \mathrm{kV}$, and then, hardness decreased with increasing peak voltage. The proper bias voltages for high hardness were obtained under both DC and pulse bias voltages. The same test was carried out on the DLC films deposited by electron beam ion plating and by sputtering, and $H$ values of both were approximately $20 \mathrm{GPa}$. The $H$ value of the silicon substrate was $13 \mathrm{GPa}$.

The scatter diagram of the modulus of dissipation and $E / H$ dependence on $H$ is shown in Figure 5. A high positive correlation was observed between the modulus of dissipation, $E / H$, and $H$, because their correlation coefficient $R$ and coefficient of determination $R^{2}$ were as high as 0.82 and 0.65 , respectively. The relationships between the moduli of dissipation in these nanoindentation tests are expressed, as shown in Figure 5.

All tested DLC films deposited with ground, floating, and DC and pulse bias voltages can be expressed in one mastering curve. The hardest $-50 \mathrm{~V}$ DC biased DLC film showed a low modulus of dissipation and $E / H$. Therefore, these FCVADLC films show excellent resistance to plastic deformation. Moreover, when the DC bias voltage was reduced from $-50 \mathrm{~V}$ to $-150 \mathrm{~V}$, the modulus of dissipation and $E / H$ increased. The modulus of dissipation and $E / H$ of DLC films deposited with ground were larger than those of the other films. The modulus of dissipation of DLC films deposited with ground and with $-2.0 \mathrm{kV}$ pulse peak voltage was approximately $25 \%$ and $28 \%$, respectively. Under the same test conditions, the modulus of dissipation of the DLC films deposited by electron beam ion plating was approximately $25 \%$, which is similar to that of DLC films deposited with ground.

For very hard materials, it is difficult to induce plastic deformation. The value of $E / H$ ranges from 14 to 20 for conventional materials such as metals. In the case of the DLC films deposited with bias voltage by an FCVA method, 


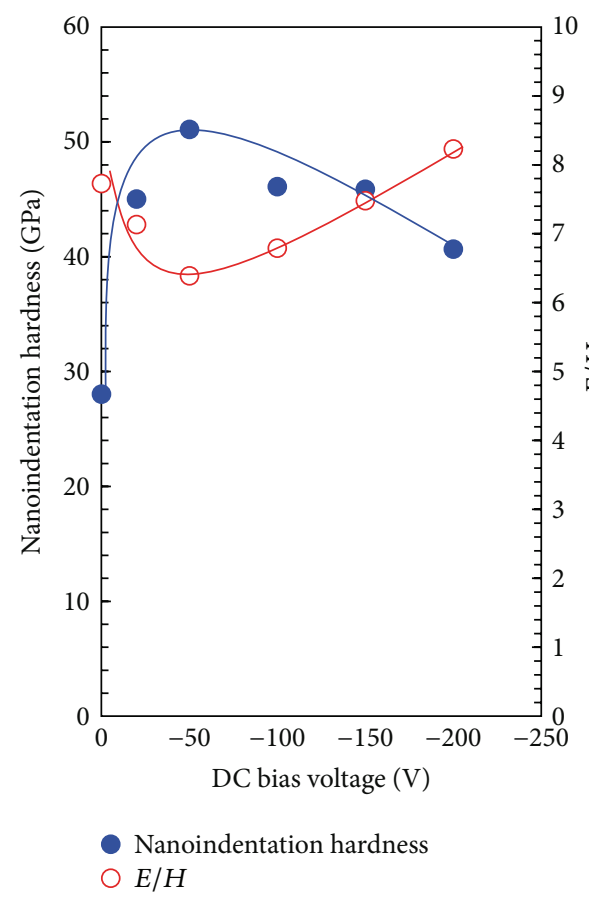

(a)

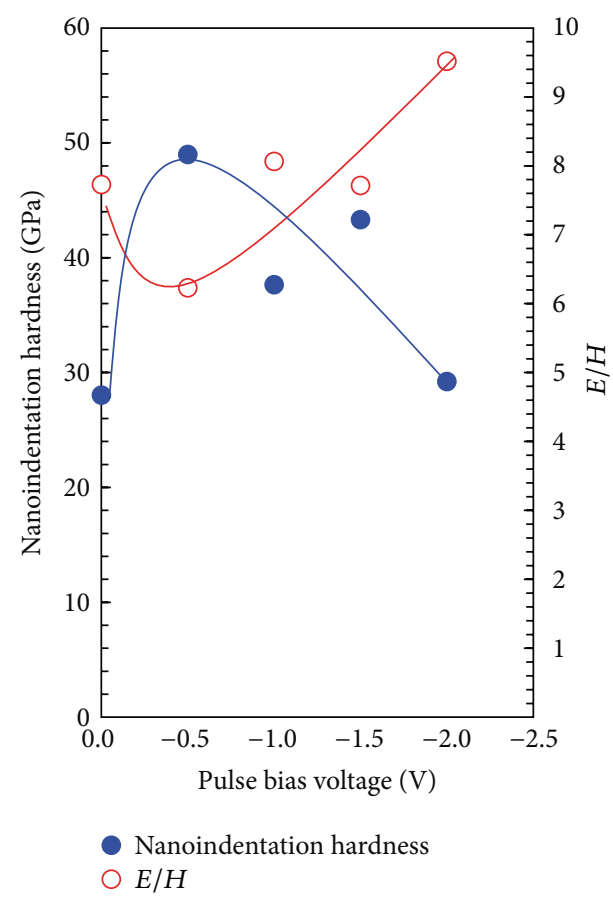

(b)

FIGURE 4: Effects of (a) DC bias voltage and (b) pulse bias voltage on nanoindentation hardness $(H)$.

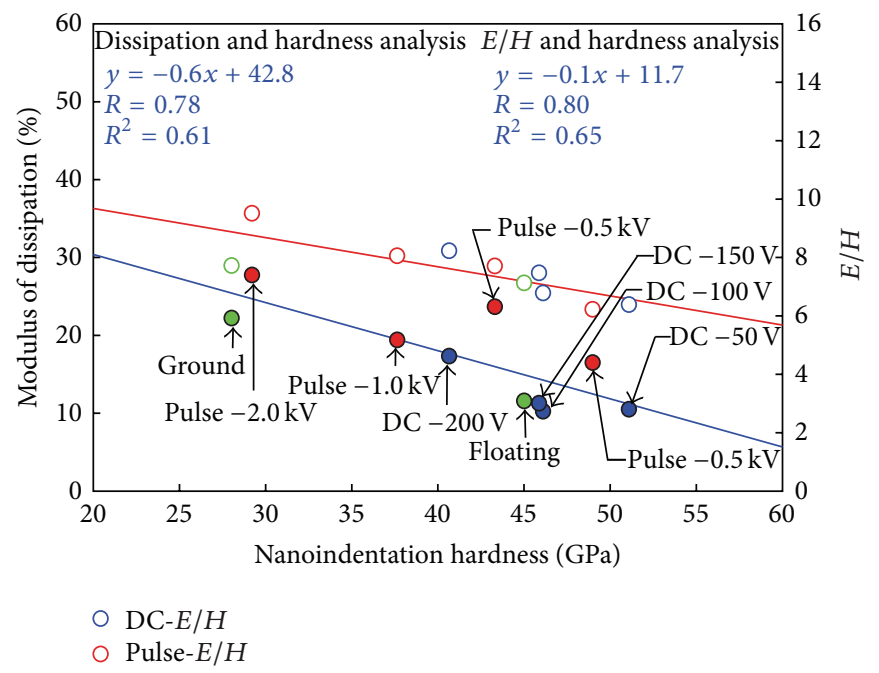

FIgURE 5: Scatter diagram of modulus of dissipation, $E / H$, and $H$ for DLC films deposited with 10 different bias voltages.

the value of $E / H$ was very small, about 10.0. From the results of the nanoindentation test, we conclude that the DLC films deposited by the FCVA method exhibit superior resistance to plastic deformation.

3.3. Nanowear Properties. A nanowear test was carried out by AFM to evaluate the dependence of nanowear resistance properties of the FCVA-DLC films on bias voltage. Figure 6(a) shows the nanowear profiles of DLC films deposited with $-50 \mathrm{~V}$ DC (A) and $-1.5 \mathrm{kV}$ pulse (B) bias voltage compared with ground (C). A quantificational analysis was carried out to evaluate the wear depth of an atomic order. The histograms of the profiles near the wear areas were calculated. For each DLC film, two peaks corresponding to the top surface and the surface of the wear groove were obtained as shown in Figure 6(b). The wear depth was estimated from the distance between central values of these two peaks. The atomic radius of carbon is approximately $0.07 \mathrm{~nm}$, and according to this method the atomic scale of wear depth can be evaluated. For DLC films deposited with ground, the peak of the top surface was broad due to the 


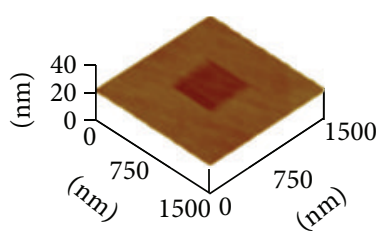

(A) DC bias $-50 \mathrm{~V}$

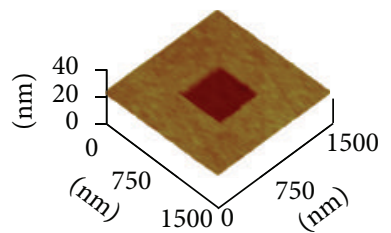

(B) Pulse $-1.5 \mathrm{kV}$

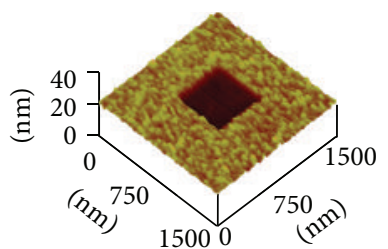

(C) Ground

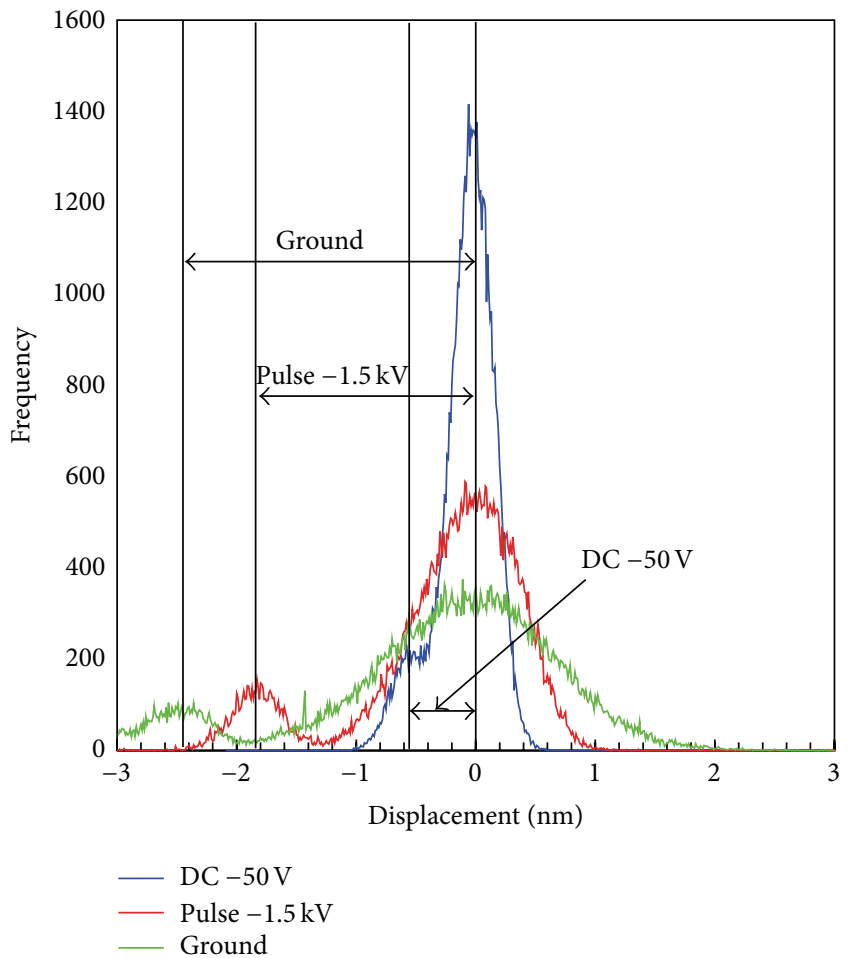

(b)

FIGURE 6: Nanowear profile and histogram of wear surfaces.

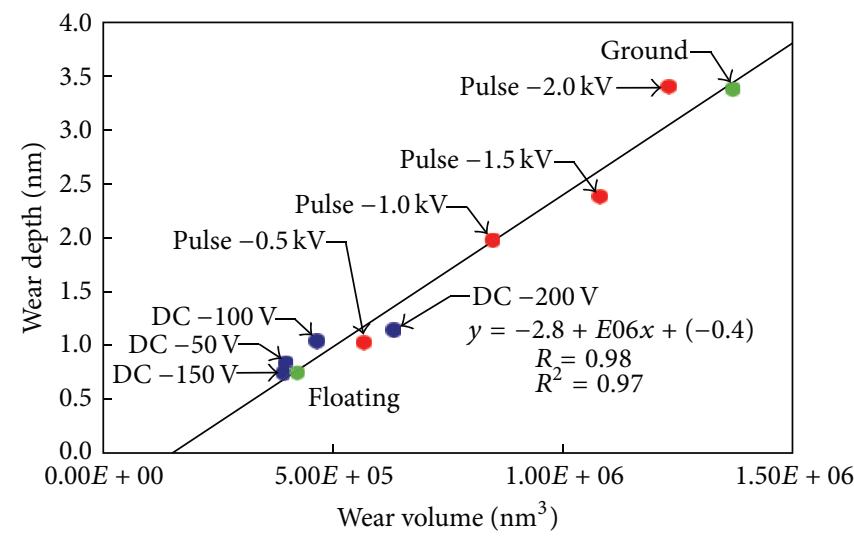

FIGURE 7: Scatter diagram of wear depth and wear volume for DLC films deposited with 10 different bias voltages.

large surface roughness, and the peak of bottom surface was separated from the top surface due to the deep wear depth. By contrast, on DLC films prepared with DC $-50 \mathrm{~V}$, the wear groove is flat and the surface roughness is low. Nearly $0.6 \mathrm{~nm}$ differences between the two peaks of these DLC films were observed. For the DLC film deposited with $-1.5 \mathrm{kV}$ pulse bias voltage, the wear depth was $1.8 \mathrm{~nm}$, whereas for those deposited with ground the wear depth was $2.5 \mathrm{~nm}$.

Figure 7 shows the scatter diagram of wear depth and wear volume for films deposited with the 10 different bias voltages. A high positive correlation was found between wear depth and wear volume, and the correlation coefficient was
$R=0.91$. The wear depths of films deposited with pulse bias voltage were slightly greater than those of films deposited with DC bias voltage. The wear depths of DLC films deposited with both $-2.0 \mathrm{kV}$ pulse bias voltage and ground exhibited similar large values. Figure 8 shows the scatter diagram of wear depth and $H$ for films deposited with the 10 different bias voltages. A strong negative correlation was found between wear depth and $H$, and the correlation coefficient was $R=$ 0.87 . The extremely thin wear depths, which were less than $4 \mathrm{~nm}$, reveal that the clear differences in the nanotribological properties of films deposited under different conditions can be evaluated. 


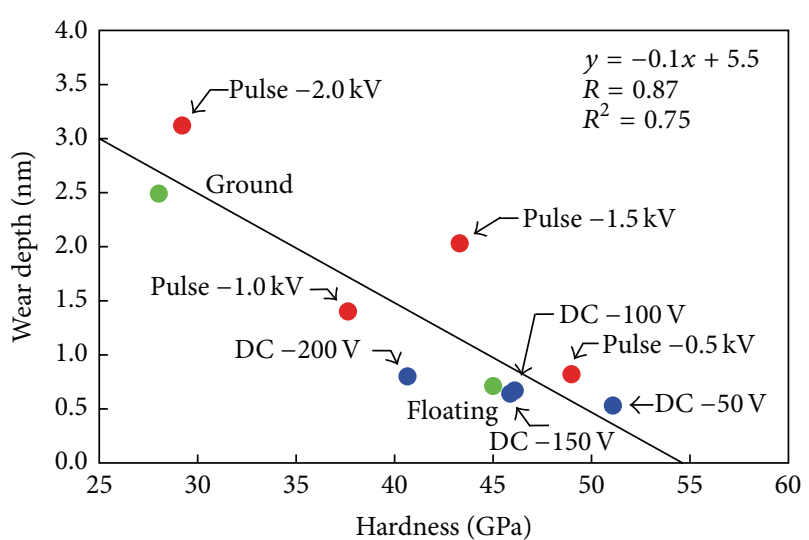

FIGURE 8: Scatter diagram of wear depth and nanoindentation hardness for DLC films deposited with 10 different bias voltages.

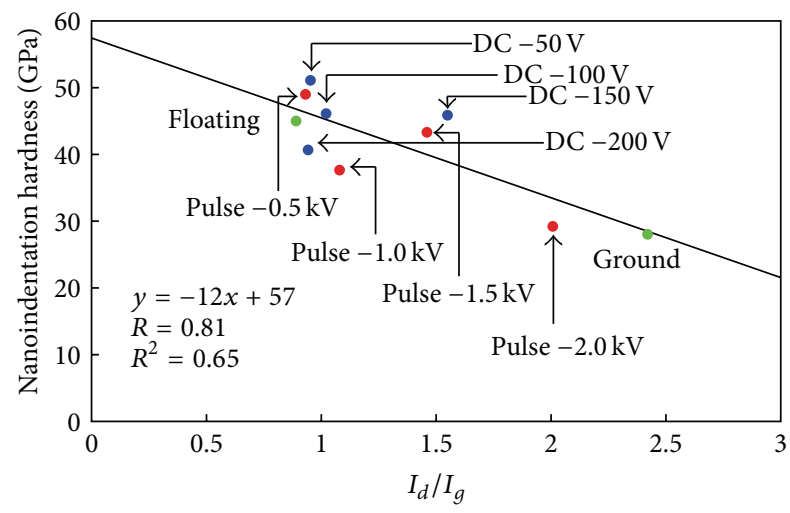

FIGURE 9: Scatter diagram of nanoindentation hardness and $I_{d} / I_{g}$ for DLC films deposited with 10 different bias voltages.

The scatter diagram of $I_{d} / I_{g}$ and $H$ for films deposited with the 10 different bias voltages is shown in Figure 9. $H$ decreased with increasing $I_{d} / I_{g}$, and a strong negative correlation was identified between $H$ and $I_{d} / I_{g}$, with a correlation coefficient as high as $R=0.81$. By contrast, $H$ and $G$ position were less correlated, with a correlation coefficient of $R=0.56$.

The scatter diagram of nanowear depth and $I_{d} / I_{g}$ for films deposited with the 10 different bias voltages is shown in Figure 10. A strong positive correlation was observed between nanowear depth and $I_{d} / I_{g}$, with a correlation coefficient as high as $R=0.82$. These results show that the nanotribological properties such as $H$ and nanowear resistance are highly correlated with $I_{d} / I_{g}$ and highly dependent on the nanostructures of the films.

3.4. Tribological Properties Evaluated by Ball-on-Disk Tribotest. Using a ball-on-disk type tribotester, the frictional properties of the DLC films were evaluated under dry and boundary lubrication conditions.

3.4.1. Frictional Properties under Dry Conditions. Figure 11 shows the relationship between the friction coefficient and the number of sliding cycles under dry conditions. For

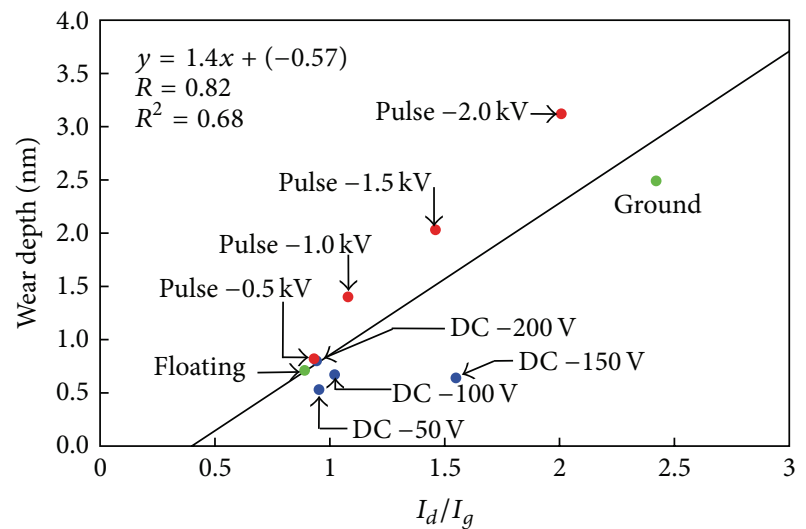

FIGURE 10: Scatter diagram of wear depth and $I_{d} / I_{g}$ for DLC films deposited with 10 different bias voltages.

the DLC films deposited with ground, the friction coefficient increased with the number of sliding cycles, with a friction coefficient as high as $0.3 \sim 0.5$. The friction coefficient of the DLC films deposited with floating voltage showed a minimum value at 0.2 . The friction coefficients of the DLC films deposited with both DC and pulse bias voltages were approximately $0.2 \sim 0.3$. These friction coefficients decreased and then became saturated with additional sliding cycles.

Figure 12 shows the dependence of the average friction coefficient of DLC films on bias voltage. DLC films deposited with floating voltage exhibited the lowest friction coefficient among all the samples. For DLC films deposited with $-1.0 \mathrm{kV}$ pulse bias voltage, the friction coefficient was also low and was similar to that for DLC films deposited with floating voltage.

3.4.2. Frictional Properties under Boundary Lubrication Conditions with Z-20 and Modifier (MoDTC) Lubricant. Evaluation of boundary lubrication properties was carried out using Z-20 with added modifier (MoDTC) lubricant. The average friction coefficients of DLC films are shown in Figure 13. DLC films deposited with all DC bias voltages and the ground exhibited low friction coefficients, which were near 0.1. The lowest friction coefficient of DLC films deposited at $-150 \mathrm{~V}$ was nearly 0.09 . For DLC films deposited with pulse bias voltage, friction coefficients were slightly higher at approximately $0.1 \sim 0.12$. DLC films deposited with $-1.0 \mathrm{kV}$ pulse bias voltage showed the highest friction coefficient value at approximately 0.12 .

3.4.3. Friction Properties under Boundary Lubrication with Refined Water. Under boundary lubrication with refined water, the friction reduction effect was less than that obtained using the Z-20 with MoDTC lubricant as shown in Figure 14. The change in friction properties compared to those obtained under dry conditions was different with refined water. For example, the friction coefficient of DLC films deposited with floating voltage was high at approximately 0.35 . By contrast, under dry conditions the friction coefficient was the lowest. For films deposited with floating voltage, the 


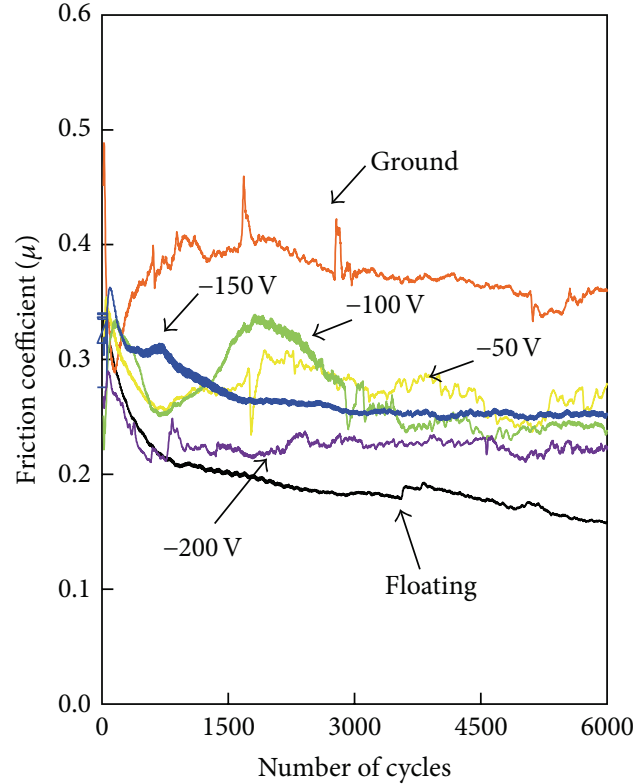

(a)

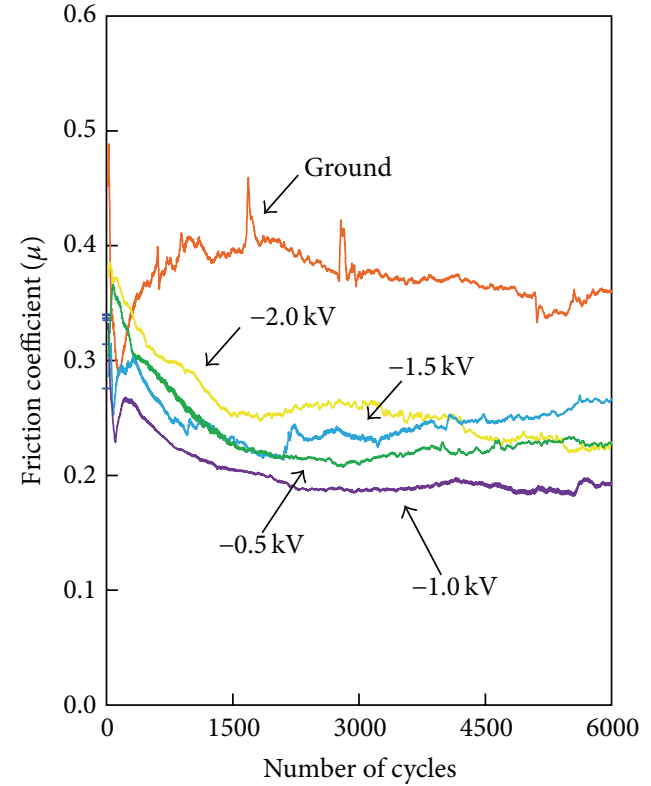

(b)

FIGURE 11: Friction properties of various biased DLC films deposited with (a) DC bias and (b) pulse bias voltage (load: 5.0 N, dry conditions).

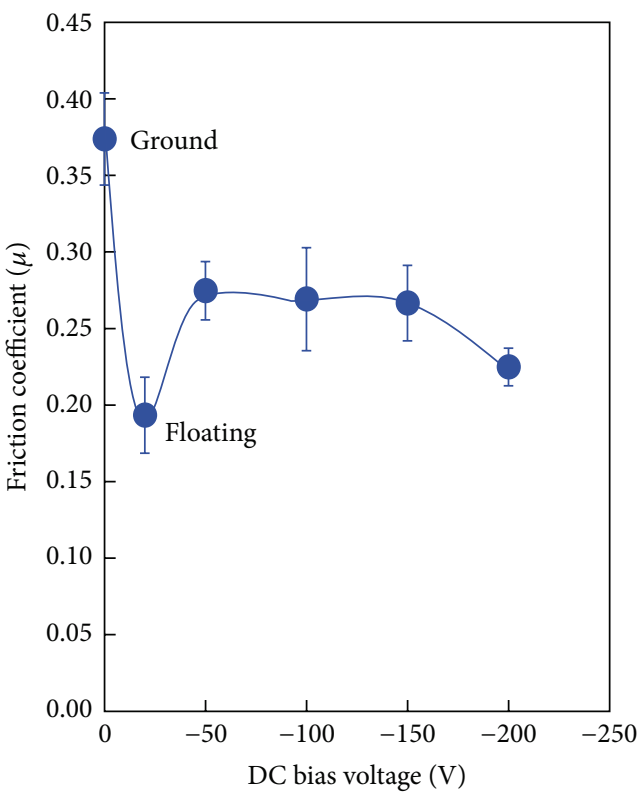

(a)

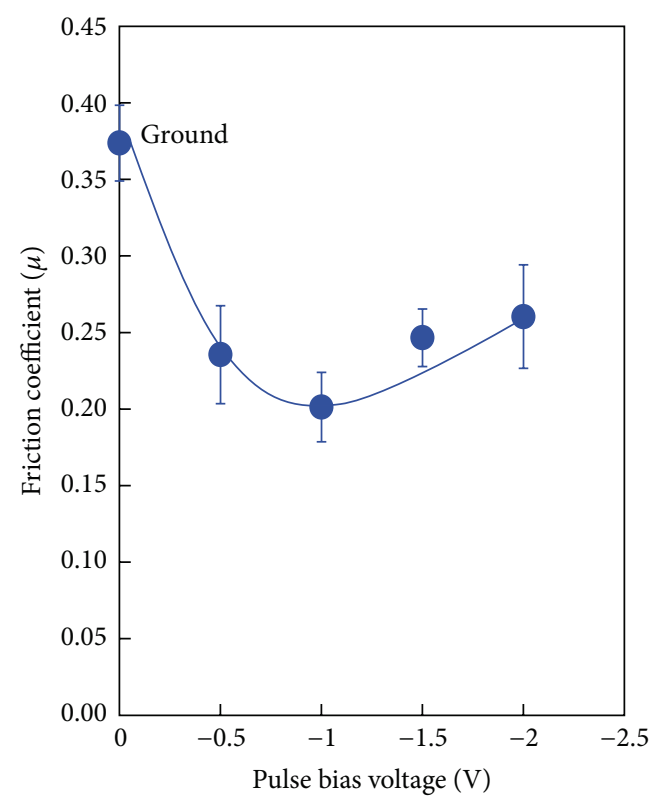

(b)

FIGURE 12: Average friction coefficient of DLC films under dry conditions.

friction exhibited inconsistent fluctuation at the beginning of the experiment. The friction coefficient of DLC films deposited with DC bias voltage was stable at approximately 0.15 . The lowest friction coefficient of 0.1 was observed for DLC films deposited with ground. In addition, the average friction coefficients of DLC films deposited with pulse bias voltage were greater than those for DLC films deposited with DC bias voltage. Overall, the friction coefficients fluctuated inconsistently from 0.2 to 0.4 , similarly as under dry conditions. The friction coefficient of DLC films deposited with $-1.0 \mathrm{kV}$ pulse peak voltage reached as high as 0.4 and then decreased with an increase in peak voltage.

3.4.4. Damage to DLC Films after Friction Testing. Under dry conditions, no visible damage to most of the FCVADLC film-coated samples was observed. Figure 15 shows an example of wear tracks formed with the use of Z-20 with MoDTC lubricant. The damage to DLC films deposited 


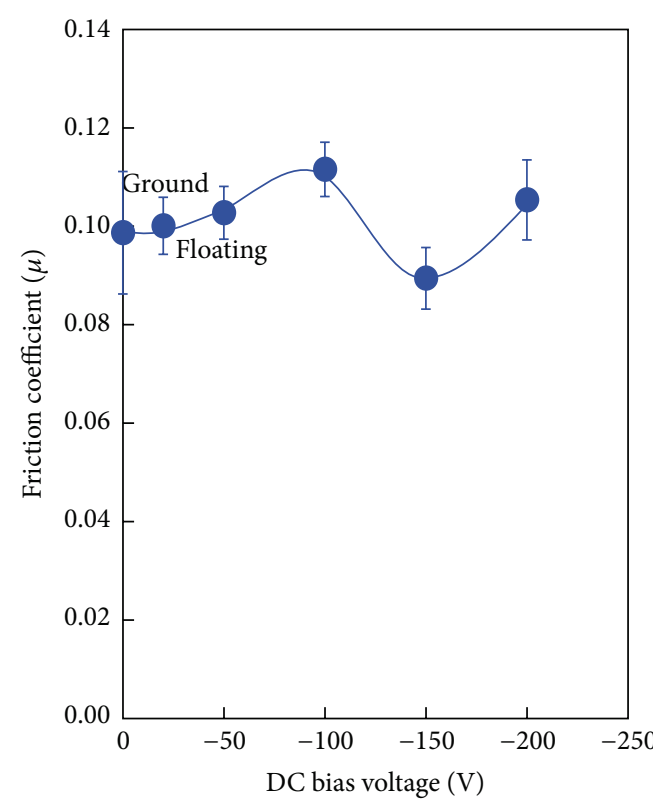

(a)

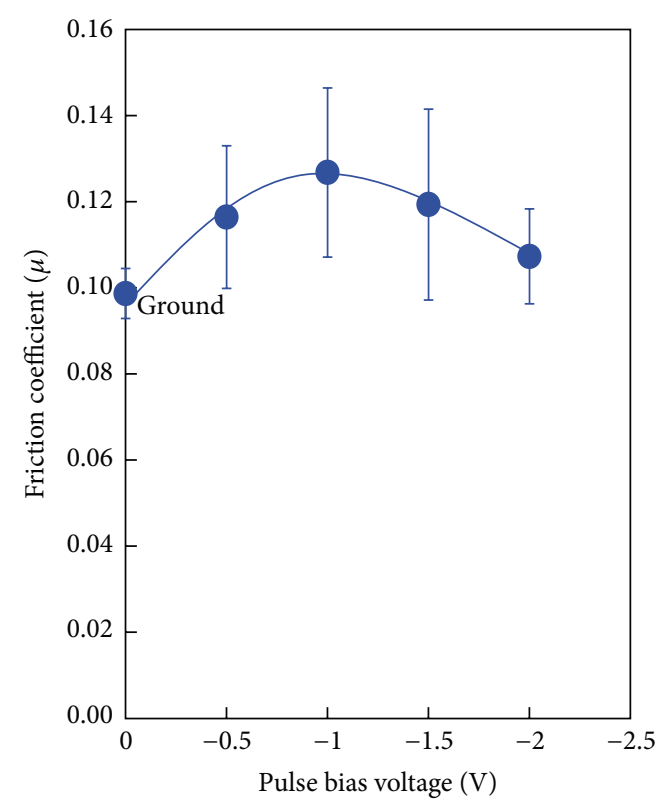

(b)

FIGURE 13: Average friction coefficient of DLC films deposited with (a) DC bias and (b) pulse bias voltage under lubrication using Z-20 with MoDTC.

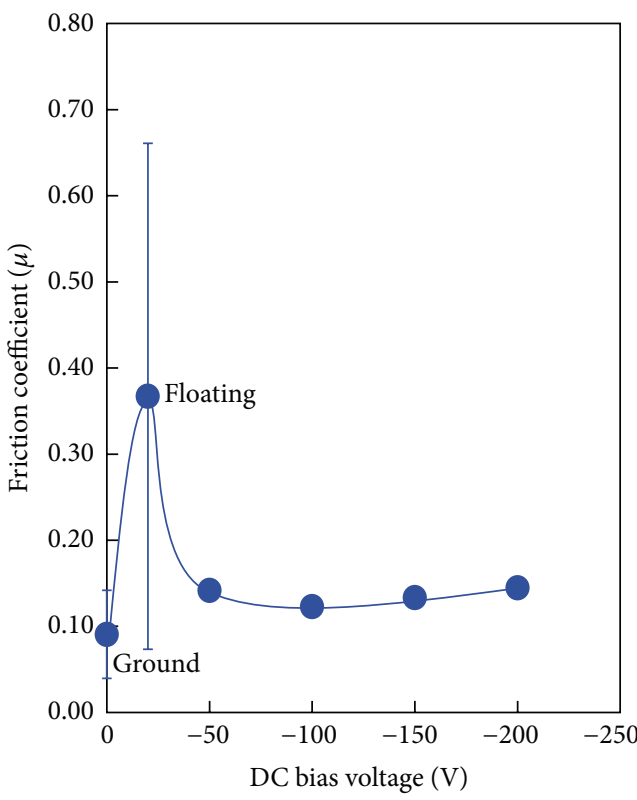

(a)

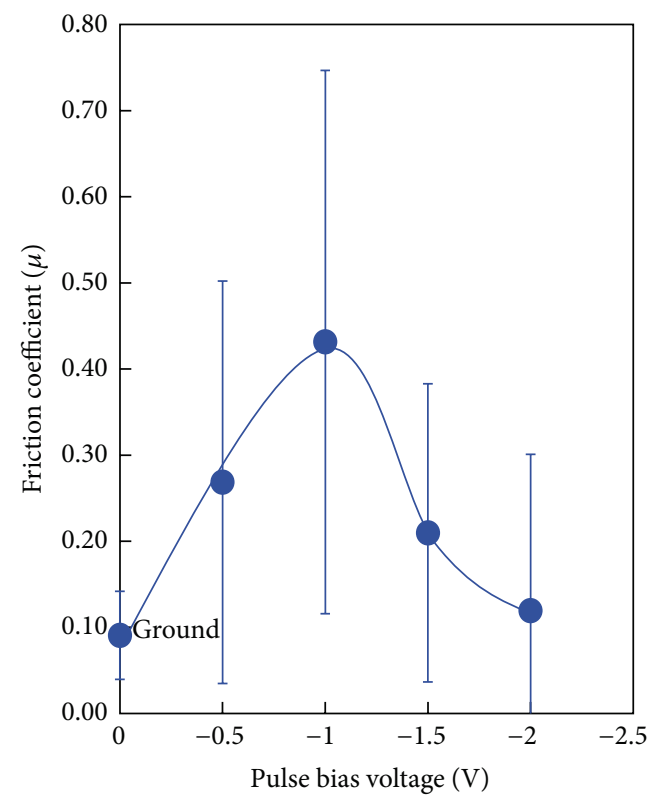

(b)

FIGURE 14: Average friction coefficient of DLC films deposited with (a) DC bias and (b) pulse bias voltage under lubrication using refined water.

with DC bias voltage and floating voltage was difficult to observe under an optical microscope. By contrast, clear damage to DLC films deposited with pulse bias voltage and ground was observed. Under water boundary lubrication, less damage was observed on DLC films deposited with DC bias voltage than on the others as shown in Figure 16. On the other hand, DLC films deposited with pulse bias voltage, ground, and floating voltage showed considerable damage, especially those deposited with ground, which showed the most damage. Under lubrication with motor oil or water, severe wear damage was formed by friction. This deduced that peeled hard and brittle films act as abrasives.

The damaged states of the tested DLC films are summarized in Table 3 . The extent of damage caused was divided 

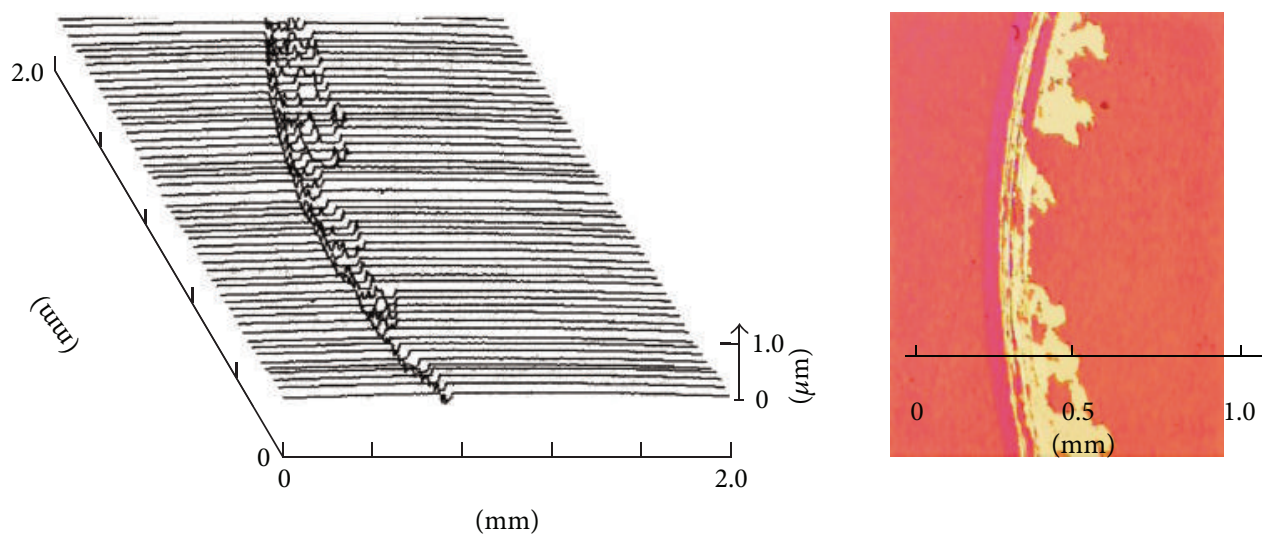

(a) Ground

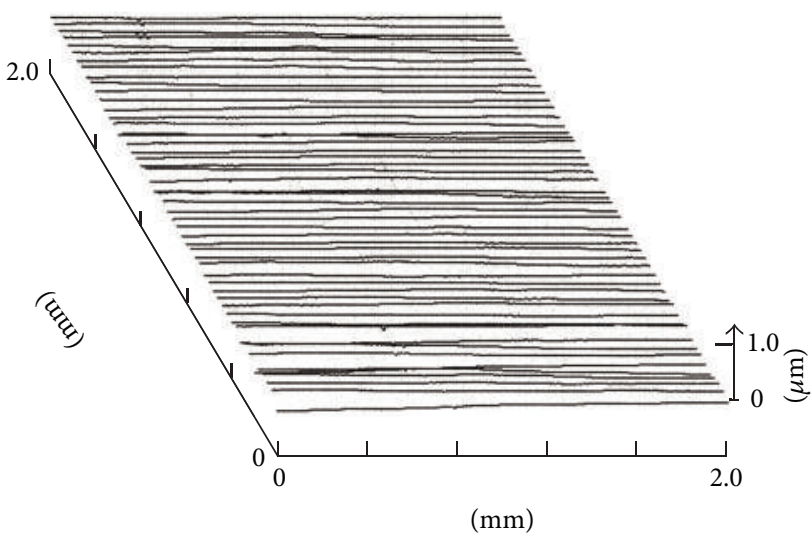

(b) $\mathrm{DC}-100 \mathrm{~V}$

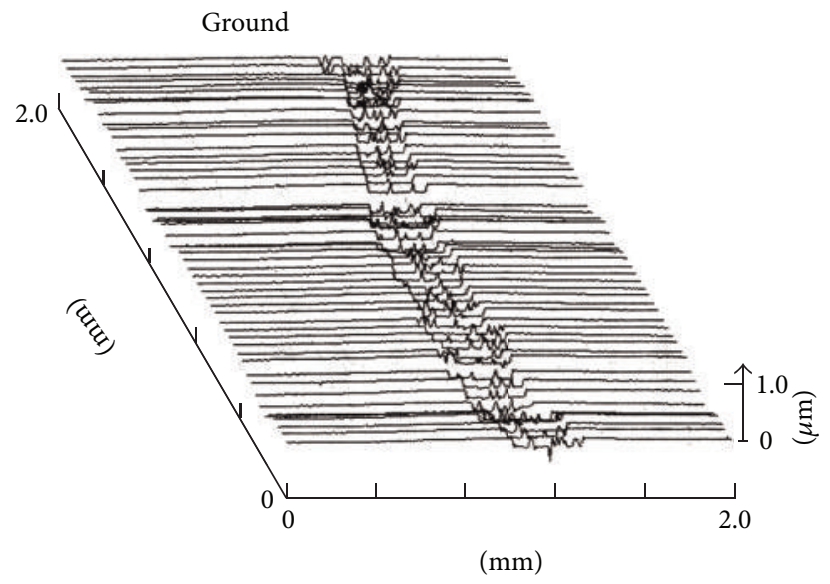

(c) Pulse $-1.0 \mathrm{kV}$

FIGURE 15: Wear profiles of DLC films deposited with (a) ground, (b) DC at $-100 \mathrm{~V}$, and (c) pulse bias at $-1.0 \mathrm{kV}$ under lubrication using Z-20 with MoDTC.

into three levels. At the first level, the damage could be observed clearly by optical microscopy, and the profile measurement was expressed as severe damage, $\times$. At the second level, the damage was difficult to observe by optical microscopy, and the profile measurement was expressed as slight damage, $\triangle$. At the third level, the damage could not be observed by optical microscopy, and the profile measurement was expressed as no damage, $O$. In particular, DLC films deposited with DC bias voltages showed superior wear resistance under dry, water, and oil boundary lubrication conditions.

3.4.5. Correlation of Nano- and Macrotribological Properties. Generally, the friction coefficient depends on hardness and Young's modulus. The scatter diagram of friction coefficients shows dependence on hardness and Young's modulus for the 10 types of DLC films deposited with bias voltage under dry conditions, and a negative correlation between the friction coefficient and hardness is shown in Figure 17. The correlation coefficients, $R$, of the friction coefficient with hardness and with $E$ was as large as 0.47 and 0.69 , respectively, as shown in Figure 10. This decrease in friction coefficient is attributed to the decrease in the contact area with increasing hardness and Young's modulus. Under Z-20 with MoDTC and water boundary lubrication, the regression between the friction
TABLE 2: Friction and lubrication properties test conditions.

\begin{tabular}{lc}
\hline Load & $5.0 \mathrm{~N}$ \\
Sliding speed & $31.4 \mathrm{~mm} / \mathrm{s}$ \\
Ball indenter & ANSI $440 \mathrm{C}$ (radius $=3.0 \mathrm{~mm}$ ) \\
& Dry condition \\
Environment & Water lubrication (refined water) \\
& Motor oil lubrication (Z-20; MO-DTC containing) \\
\hline
\end{tabular}

coefficient and $H$ is very weak. Under boundary lubrication, the friction coefficients were influenced by surface damage (Table 2).

There is little correlation between the specific wear rate and $H$ of the prepared FCVA-DLC films. The damage to DLC films deposited without bias voltage was considerable, and the damage to DLC films deposited with pulse bias voltage was greater than that observed on films deposited with DC bias voltage. Therefore, the specific wear rates determined in the friction test seemed to be affected by other factors such as the adhesion strength between the DLC films and the substrate. 


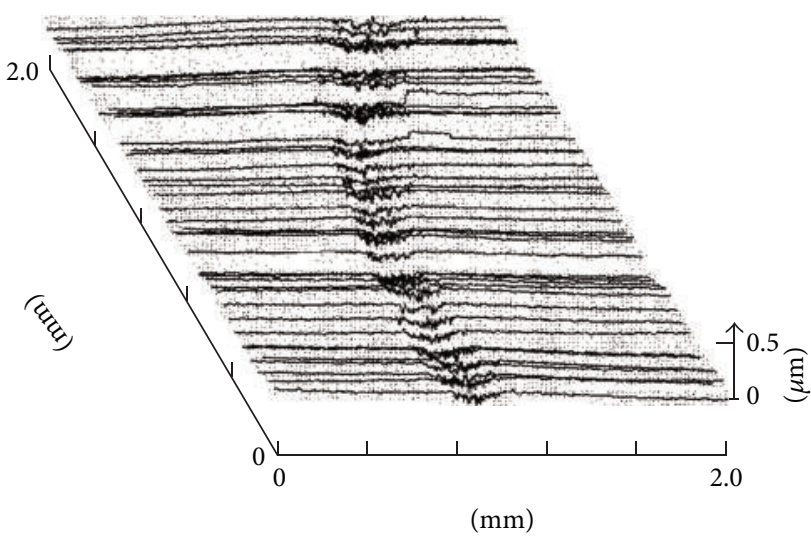

(a) Ground

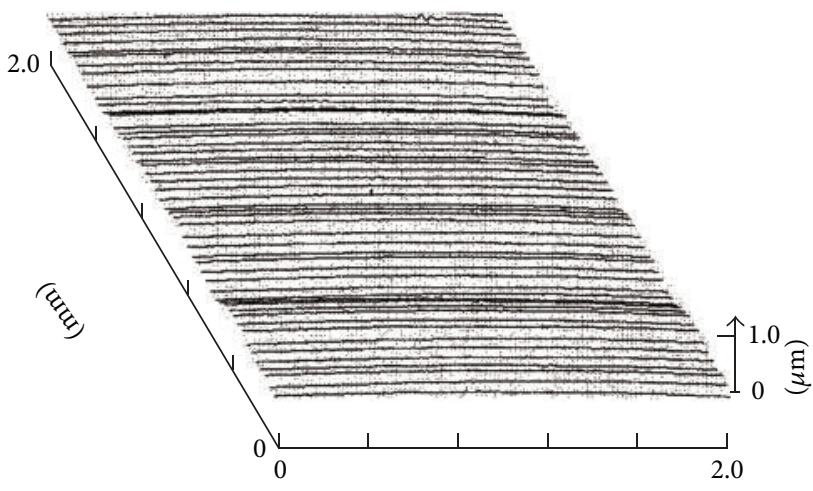

(mm)

(b) $\mathrm{DC}-100 \mathrm{~V}$

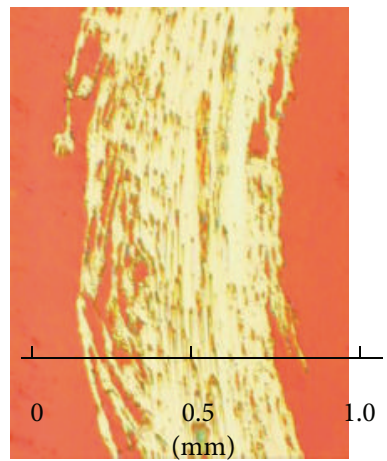

Pulse $-1.0 \mathrm{kV}$

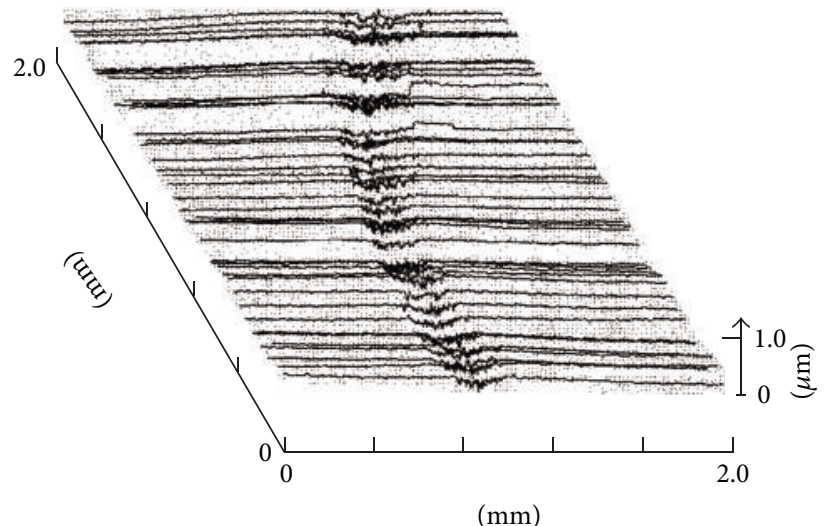

(c) Pulse $-1.0 \mathrm{kV}$

FIGURE 16: Wear profiles under lubrication using water for DLC films deposited with (a) ground, (b) DC at -100 V, and (c) pulse bias at $-1.0 \mathrm{kV}$.

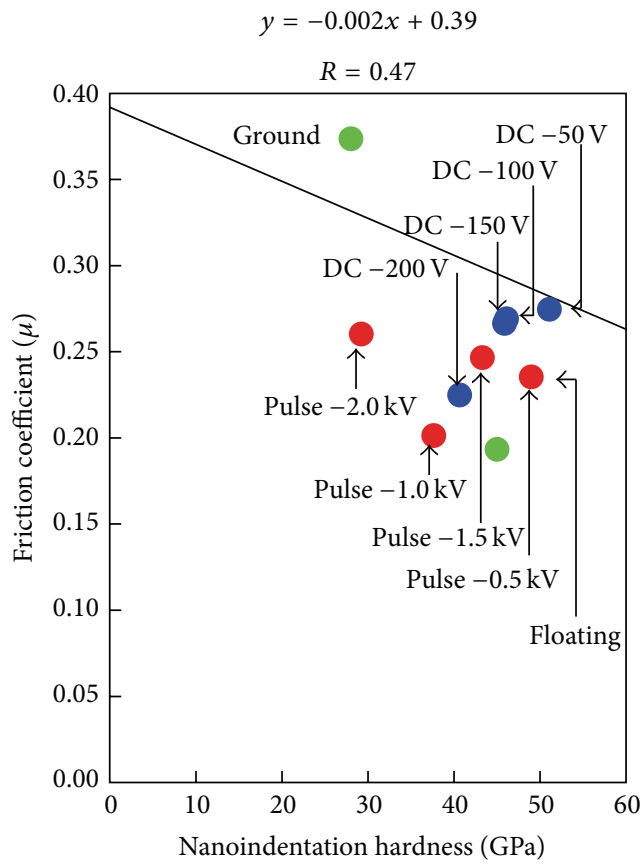

(a)

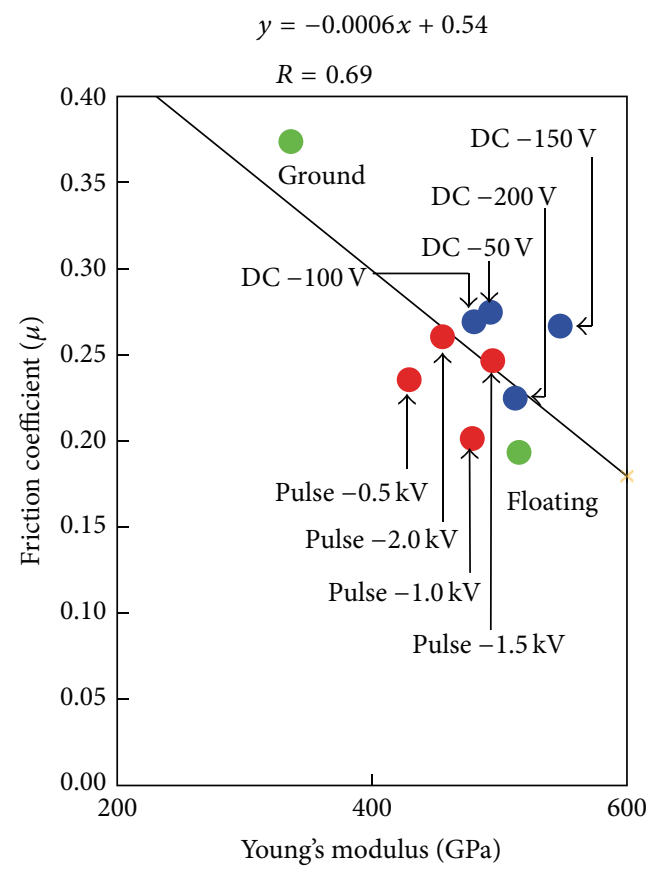

(b)

FIGURE 17: Scatter diagram of friction coefficient, nanoindentation hardness, and Young's modulus. 
TABLE 3: Sliding damage and specific wear rate $\left(\mathrm{nm}^{2} / \mathrm{N}\right)$.

\begin{tabular}{|c|c|c|c|c|c|c|c|c|c|c|}
\hline & \multicolumn{4}{|c|}{$\mathrm{DC}$} & \multicolumn{4}{|c|}{ Pulse } & \multirow{2}{*}{$\begin{array}{c}\text { Ground } \\
0 \mathrm{~V}\end{array}$} & \multirow{2}{*}{$\begin{array}{c}\text { Floating } \\
0 \mathrm{~V}\end{array}$} \\
\hline & $-50 \mathrm{~V}$ & $-100 \mathrm{~V}$ & $-150 \mathrm{~V}$ & $-200 \mathrm{~V}$ & $-0.5 \mathrm{kV}$ & $-1.0 \mathrm{kV}$ & $-1.5 \mathrm{kV}$ & $-2.0 \mathrm{kV}$ & & \\
\hline \multirow[t]{2}{*}{ Dry } & \multirow[t]{2}{*}{$\mathrm{O}$} & \multirow[t]{2}{*}{$\mathrm{O}$} & \multirow[t]{2}{*}{$\mathrm{O}$} & \multirow[t]{2}{*}{ O } & \multirow[t]{2}{*}{ O } & \multirow[t]{2}{*}{ O } & \multirow[t]{2}{*}{ O } & $\triangle$ & $\triangle$ & \multirow[t]{2}{*}{$\bigcirc$} \\
\hline & & & & & & & & 0.21 & 0.20 & \\
\hline \multirow{2}{*}{ Oil } & \multirow{2}{*}{ O } & \multirow{2}{*}{0} & \multirow{2}{*}{$\mathrm{O}$} & $\triangle$ & $x$ & $x$ & $\times$ & $x$ & $x$ & $\triangle$ \\
\hline & & & & 0.61 & 6.54 & 9.26 & 8.88 & 8.20 & 6.76 & 0.24 \\
\hline \multirow{2}{*}{ Water } & $x$ & $\triangle$ & $\triangle$ & $\triangle$ & $x$ & $x$ & $x$ & $x$ & $x$ & $x$ \\
\hline & 1.35 & 0.62 & 0.86 & 0.38 & 5.0 & 1.80 & 2.42 & 1.46 & 6.92 & 5.28 \\
\hline
\end{tabular}

O: damage free; $\triangle$ : less damage; $\times$ : severe damage.

\section{Conclusions}

The nano- and macrotribological properties of DLC films deposited by the FCVA method were evaluated, and the results are summarized as follows.

(1) To determine resistance to plastic deformation, $H$, the modulus of dissipation, and $E / H$ were measured using a nanoindentation test. Strong correlations between hardness, modulus of dissipation, and $E / H$ were observed. The FCVA-DLC films deposited with DC bias voltage showed high resistance to plastic deformation. The DLC films deposited with a DC bias voltage of $-50 \mathrm{~V}$ exhibited the greatest hardness (approximately $50 \mathrm{GPa}$ ), a low modulus of dissipation, and low $E / H$.

(2) Nanowear properties of FCVA-DLC films at less than $4 \mathrm{~nm}$ depth were evaluated by the AFM. The wear depths of DLC films deposited with floating and DC bias voltage were shallow at less than $1.0 \mathrm{~nm}$. A strong negative correlation was found between $H$ and wear depth.

(3) A positive correlation was observed between $H$ and the Raman peak ratio $I_{d} / I_{g}$, whereas a negative correlation was observed between wear depth and $I_{d} / I_{g}$. These results show that nanotribological properties such as $H$ and nanowear resistance are highly correlated with $I_{d} / I_{g}$ and highly dependent on the films' nanostructures.

(4) Under dry conditions, DLC films deposited with floating and pulse bias voltages of $-1.0 \mathrm{kV}$ exhibited low friction coefficients $(\mu=0.2)$. Under boundary lubrication with MoDTC-containing Z-20, FCVADLC films deposited with DC bias voltage also showed low friction coefficients $(\mu=0.1)$. Under water boundary lubrication, the average friction coefficients of DLC films deposited with DC bias voltage also were low at about 0.1 .

(5) Under dry conditions, no visible damage could be observed on any of the FCVA-DLC films after friction testing. The damage to DLC films deposited with DC bias voltage was also very little under boundary lubrication with either MoDTC-containing Z-20 lubricant or water. By contrast, the FCVA-DLC films deposited with pulse bias voltage and ground clearly exhibited visible damage.

(6) The friction coefficient determined by a ball-on-disk test was correlated with $H$ under dry conditions. However, with boundary lubrication, the friction coefficient and the specific wear rate showed little correlation with $H$. These results suggest that the friction and wear behaviors of these films are influenced by other factors such as the adhesion strength between the film and substrate.

\section{Conflict of Interests}

The authors declare that there is no conflict of interests regarding the publication of this paper.

\section{Acknowledgment}

This research was partly supported by the Storage Research Consortium (SRC).

\section{References}

[1] S. Miyake and R. Kaneko, "Microtribological properties and potential applications of hard, lubricating coatings," Thin Solid Films, vol. 212, no. 1-2, pp. 256-261, 1992.

[2] S. Miyake, R. Kaneko, Y. Kikuya, and I. Sugimoto, "Microtribological studies on fluorinated carbon films," Journal of Tribology, vol. 113, no. 2, pp. 384-389, 1991.

[3] S. Miyake, Y. Yasuda, M. Kano, and Y. Mabuchi, "Slidably movable member and method of producing same," Japanese patent 3555844, U.S. patent 6844068, DE patent 10017459C2, 2002.

[4] Y. Okamoto, Y. Yasuda, and S. Miyake, "Hard carbon film slidably movable member," Japanese patent application nos. 355775 (2005), 260671 (2005), 088270 (2005), 317513 (2004), 317498 (2004), 276825 (2002).

[5] M. Kano, Y. Yasuda, Y. Okamoto et al., "Ultralow friction of DLC in presence of glycerol mono-oleate (GMO)," Tribology Letters, vol. 18, no. 2, pp. 245-251, 2005.

[6] S. Miyake and M. Wang, "Nanotribology of magnetic disks," in Encyclopedia of Nanoscience and Nanotechnology, H. S. Nalwa, Ed., vol. 19, pp. 399-451, American Scientific Publishers, 2011.

[7] J. Robertson, "Ultrathin carbon coatings for magnetic storage technology," Thin Solid Films, vol. 383, no. 1-2, pp. 81-88, 2001.

[8] T. Yamamoto, H. Hyodo, S. Tsuchitani, and R. Kaneko, "Ultrathin amorphous carbon overcoats by filtered cathodic arc 
deposition," IEEE Transactions on Magnetics, vol. 39, no. 5, pp. 2201-2204, 2003.

[9] H. Hyodo, T. Yamamoto, and T. Toyoguchi, "Properties of tetrahedral amorphous carbon film by filtered cathodic arc deposition for disk overcoat," IEEE Transactions on Magnetics, vol. 37, no. 4, pp. 1789-1791, 2001.

[10] S. Miyake and S. Yamazaki, "Nanoscratch properties of extremely thin diamond-like carbon films," Wear, vol. 305, pp. 6977, 2013.

[11] S. Miyake, W. Kurosaka, and K. Oshimoto, "Nanometre scale mechanical properties of extremely thin diamond-like carbon films," Tribology-Materials, Surfaces \& Interfaces, vol. 3, no. 4, pp. 158-164, 2009.

[12] X. Shi, B. K. Tay, H. S. Tan et al., "Properties of carbon ion deposited tetrahedral amorphous carbon films as a function of ion energy," Journal of Applied Physics, vol. 79, no. 9, pp. 7234-7240, 1996.

[13] A. C. Ferrari, "Determination of bonding in diamond-like carbon by Raman spectroscopy," Diamond and Related Materials, vol. 11, no. 3-6, pp. 1053-1061, 2002.

[14] N. Taniguchi, Ed., Nanotechnology, Oxford University Press, Oxford, UK, 1996.

[15] Z. N. Farhat, Y. Ding, D. O. Northwood, and A. T. Alpas, "Nanoindentation and friction studies on Ti-based nanolaminated films," Surface and Coatings Technology, vol. 89, no. 1-2, pp. 24-30, 1997.

[16] S. Miyake, S. Watanabe, H. Miyazawa, M. Murakawa, R. Kaneko, and T. Miyamoto, "Improved microscratch hardness of ion-plated carbon film by nitrogen inclusion evaluated by atomic force microscope," Applied Physics Letters, vol. 65, no. 25, pp. 3206-3208, 1994. 

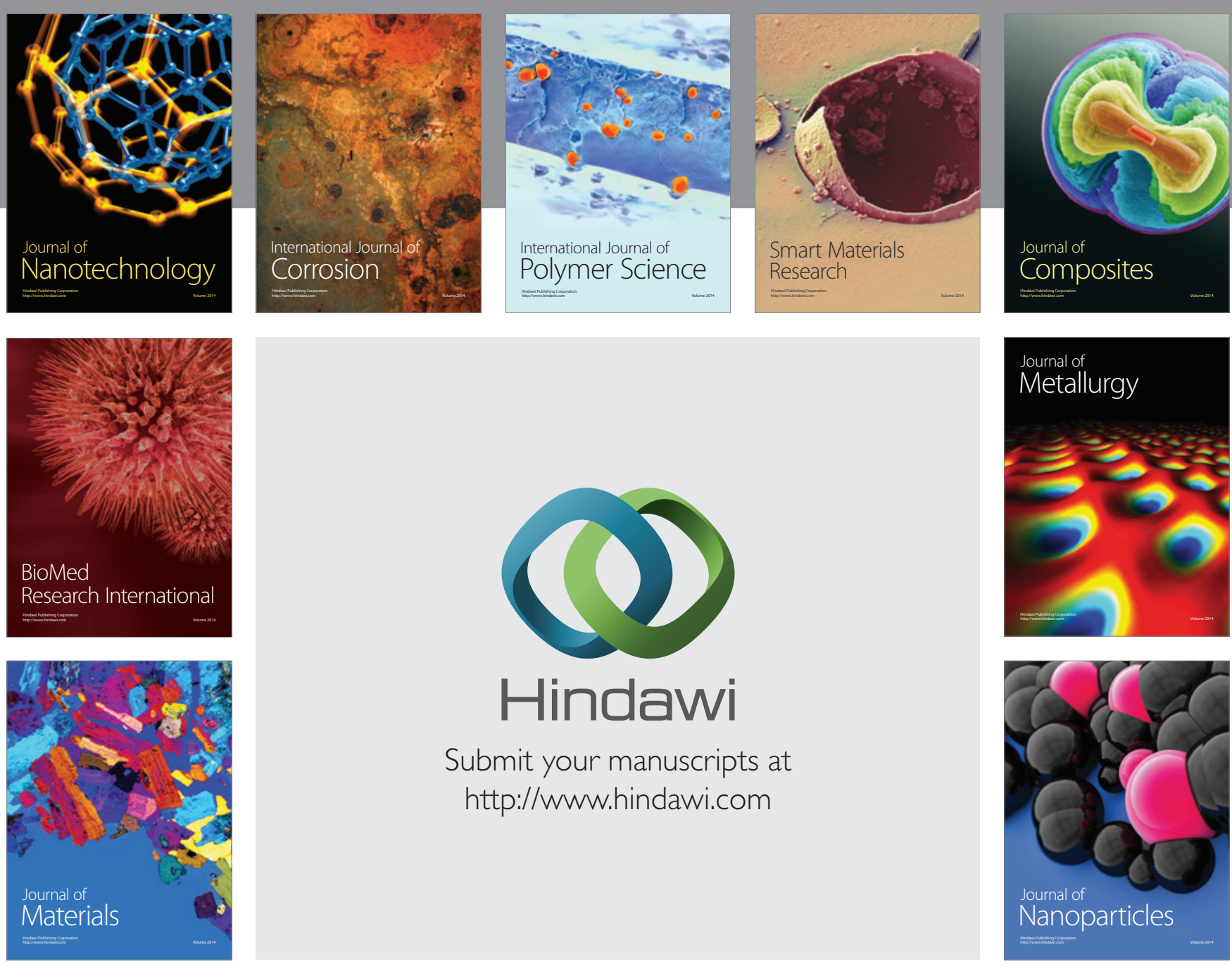

Submit your manuscripts at http://www.hindawi.com
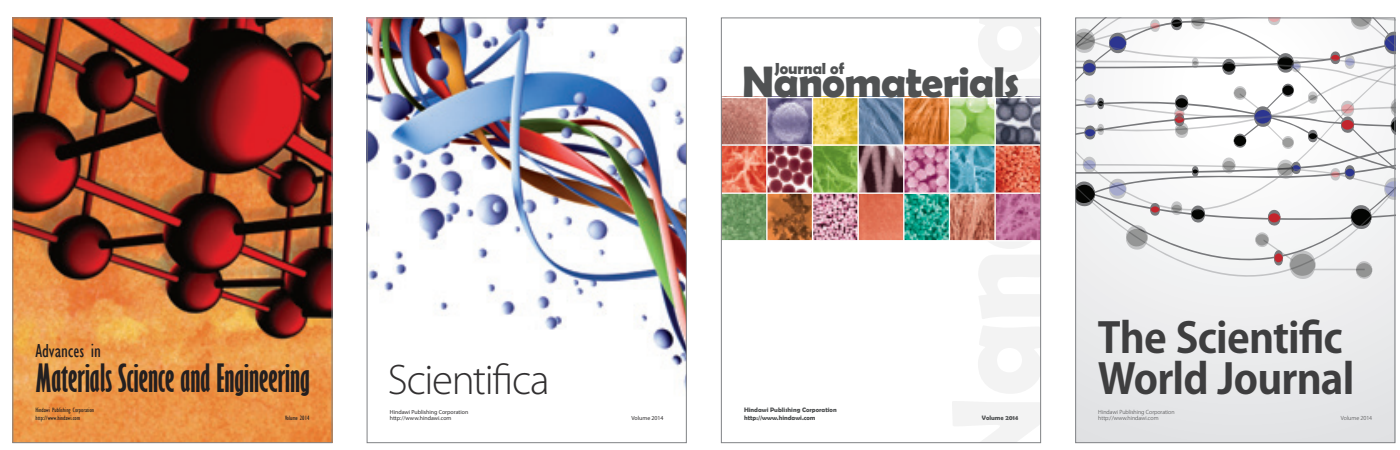

\section{The Scientific World Journal}
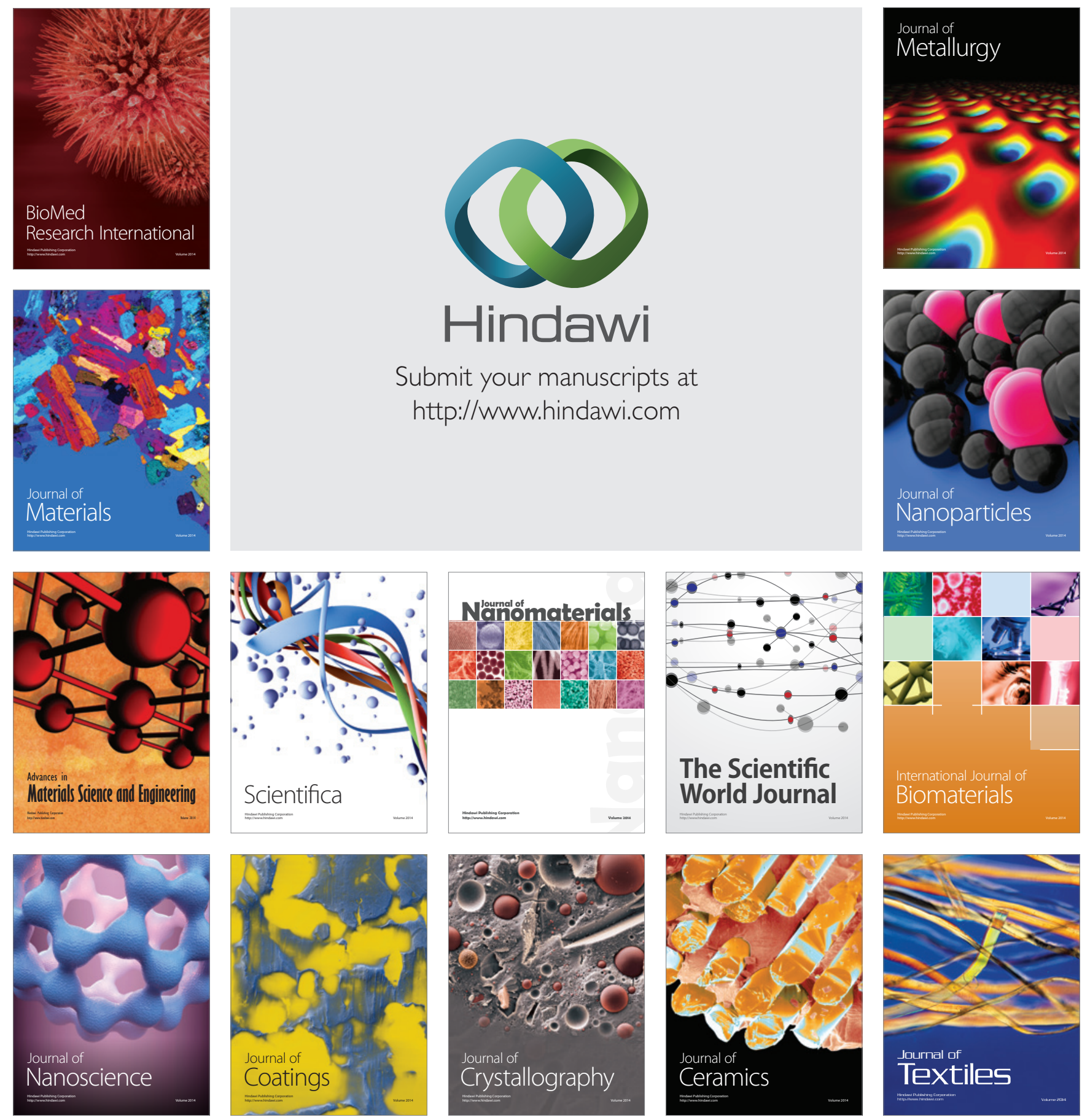